\title{
Apoptosis and electroretinogram after intravitreal injection of methotrexate in an experimental rabbit model
}

\author{
Eman Aly and Amal Ebrahim \\ 1. Research Institute of Ophthalmology, Giza, Egypt
}

\begin{abstract}
The aim of this study was to explore the changes in electroretinogram of rabbit retina and apoptosis in methotrexate-induced toxicity. Rabbits were divided into 5 groups. Group I served as control in which saline solutions was injected intravitreally. Methotrexate $(800 \mu \mathrm{g}, 1.76 \mu \mathrm{mol})$ was injected into the vitreous of both eyes of rabbits groups II, III, IV and V by an insulin injector with a 26 gauge needle under general anesthesia. Retinal function was assessed by electroretinogram (ERG) after 2, 4, 10 days and one month then animals were decapitated. The eyes were enucleated and processed for DNA fragmentation studies by gel electrophoresis to retinae and measurement of caspase- 3 activities. The results indicated a significant reduction $(p<0.05)$ in a- and b-wave, a timedependent appearance of the typical ladder pattern of internucleosomal fragmentation, a characteristic of apoptosis and increase of relative caspase- 3 activity after methotrexate intravitreal injection. Methotrexate lead to apoptosis, increase of caspase-3 and affect retinal function.
\end{abstract}

Key words: Apoptosis - Retina - Methotrexate - Electroretinogram - Rabbit

\section{Introduction}

Cell death may be conveniently classified into two broad categories: necrosis and apoptosis (Li et al. 2014). In necrosis, the cells show early plasma membrane changes, clumping of chromatin, swelling of intracellular organelles, membrane breakdown, and leakage of enzymes and proteins causing extensive inflammatory reactions (Gerschenson 1992; Wyllie 1992). In addition, necrotic cells appear in patches. In contrast, apoptotic cells are characteristically scattered throughout the tissue and initially show condensation of chromatin at the nuclear periphery and reduction of nuclear size and cell volume (Vaux 1993; Williams and Smith 1993). After gel electrophoresis, chromosomal DNA cleaved into fragments of roughly 180 base pairs (bp) and multiples (Compton 1992). Apoptotic bodies, small sealed membrane vesicles, were formed to prevent leakage toxic of dying cells and were taken up by phagocytes and neighboring cells (Johnson and Deckwerth 1993).

Apoptosis plays an important role in the regulation of cell numbers to control tissue development and maintain tissue

Correspondence to: Eman Aly, 1. Research Institute of Ophthalmology, Giza, Egypt

E-mail: em_saleh2014@hotmail.com homeostasis. Dysregulation of apoptosis has been reported in an increasing number of pathological conditions (Webb et al. 1997). In the retina, apoptotic cell death is seen in postnatal development, axotomy, ischaemia, degenerative diseases and experimental retinal detachment (Cook et al. 1995). Apoptosis has also been shown in human retina of retinoblastoma, pathological myopia, age-related macular degeneration and traumatic retinal detachment (Buchi et al. 1994).

The lymphoproliferative disorders including leukemia, reactive lymphoid hyperplasia, non-Hodgkin lymphoma, and primary central nervous system lymphoma may involve ocular structures. Since the primary central nervous system lymphoma with isolated ocular involvement is radiosensitive, early central relapses requiring combination of radiotherapy and chemotherapy may occur (DeAngelis 1992; Peterson et al. 1993; Nelson 1999). Ocular manifestations that are resistant to conventional systemic treatment may require intratechal and intravitreal chemotherapy, which is often recommended as a first line treatment.

The local and systemic administration of methotrexate (MTX) is increasingly common in ophthalmic disease. Various ophthalmic inflammatory conditions are indications for systemic therapy and intraocular lymphomas associated with primary central nervous system lymphoma have been suc- 
cessfully treated with intravitreal injections of MTX (Taylor et al. 2013). However, the effects of MTX on the retina are still under investigation. The aim of this study was to explore cell death in intravitreally injected MTX on the rabbit retina and its effect on ERG. The dosage used in the study was higher compared to the routinely used dosage, because we aim to investigate the possible experimental retinotoxic concentrations of intravitreal MTX (Frenkel et al. 2008).

\section{Materials and Methods}

Rabbits were randomly selected from the animal house facility at the Research Institute of Ophthalmology, Giza, Egypt. The experimental protocol was approved by the local ethical committee that applies ARVO (The Association for Research in Vision and Ophthalmology) statements of using animals in ophthalmic and vision research. Rabbits were kept in cages in well ventilated house, temperature of $27-30^{\circ} \mathrm{C} 12 \mathrm{~h}$ natural lights and $12 \mathrm{~h}$ darkness. All chemicals were purchased from Sigma Chemical Co. (St. Louis, MO, USA). Forty New Zealand white rabbits of either sex, weighing 2-2.5 kg were divided into 5 groups (8 rabbits each equal 16 eyes). Group I served as control in which $0.1 \mathrm{cc}$ saline solutions was injected intravitreally instead of MTX at $3 \mathrm{~mm}$ posterior to the limbus at the upper temporal quadrant.

$50 \mathrm{mg} / 2 \mathrm{ml} \mathrm{MTX}$ without preservative (Methotrexate "Ebewe" obtain MTX $8 \mathrm{mg} / \mathrm{ml}$. A volume of $0.1 \mathrm{ml}$ of the preparation (MTX $800 \mu \mathrm{g}, 1.76 \mu \mathrm{mol}$ ) was injected into the vitreous of both eyes of rabbits groups II, III, IV and V by an insulin injector with a 26 gauge needle under general anesthesia. Intravitreal injection was performed $3 \mathrm{~mm}$ posterior to the limbus at the upper temporal quadrant. Retinal function was assessed by electroretinogram (ERG) after 2, 4, 10 days and one month followed by decapitation of animals for all groups. The eyes were enucleated and processed for DNA fragmentation studies by gel electrophoresis to retinae and measurement of caspase- 3 activities.

\section{Electroretinogram}

The animals were dark-adapted for 3 hours before the electrophysiological recording. They were anesthetized intravenous by $35 \mathrm{mg} / \mathrm{kg}$ sodium thiopental, and after establishing the anaesthesia, animals were placed on the pad of an operating table where their body temperature was maintained at $37^{\circ} \mathrm{C}$. Each rabbit was positioned with its head resting to one side and local anesthetizing eye drops were also applied. The pupil of the recorded eye was dilated with topical 1\% mydriacyl. A white flash was used in this work with fixed intensity 4 lux and duration 0.2 seconds. ERGwas recorded by using sensor PS-2111 and its electrodes (PASCO,
Roseville, CA) which connect to PASPORT interface direct to the computer. One electrode was placed at the corneal periphery as active electrode. The other two electrodes were placed on the skin of the lower eyelid and on the ear, as reference and earthed electrodes. The electrodes were placed on the skin after removal the hair. The resulted electrophysiological signals were collected and analyzed by data studio 1.9.8 software (PASCO, Roseville, CA).

\section{DNA fragmentation studies by gel electrophoresis}

The rabbits were sacrificed by decapitation, where the eyes were enucleated, and then opened by corneal section through the ora serrata. After removing the corneas, the iris was pulled out by a forceps where the eye lens and the vitreous humour were jointly removed. The reaming eye cub, which contains the retina, was cut into blocks for DNA extraction and immediately frozen in liquid nitrogen. The tissue was placed into sterilized DNAase/RNase free. $40 \mu \mathrm{l}$ of $10 \%$ SDS and $4 \mu \mathrm{l}$ of $20 \mathrm{mg} / \mathrm{ml}$ proteinase $\mathrm{K}$ were added to each tissue then samples were incubated at $55^{\circ} \mathrm{C}$ in hybridization oven overnight. $175 \mu \mathrm{l}$ of buffered phenol and $175 \mu \mathrm{l}$ of chloroform/isoamyl (24:1) were added to each sample and then centrifuged at 15,000 for $20 \mathrm{~min}$. The aqueous phase was transferred to sterilized microtube. Chloroform/isoamyl (24:1) was added into the supernatant at an amount equivalent to the supernatant obtained from the last step. Then, centrifugation was done at 15,000 for $20 \mathrm{~min}$. The supernatant was transferred into new microtubes. $10 \mu \mathrm{l}$ RNase was added into each sample and was incubated at $37^{\circ} \mathrm{C}$ for $1 \mathrm{~h}$. Chloroform/isoamyl (24:1) was added into the supernatant at an amount equivalent to the supernatant obtained then centrifuged at 15,000 for $20 \mathrm{~min}$. $250 \mu \mathrm{l}$ of each supernatant was transferred into a new microtube and $7.5 \mu \mathrm{l}$ of $5 \mathrm{M} \mathrm{NaCl}$ was added into the supernatant to reach a final concentration of $0.15 \mathrm{M}$ of $\mathrm{NaCl}$ in the sample and mixed gently. Twice the volume of supernatant of $-20^{\circ} \mathrm{C}, 100 \%$ ethanol was added. Samples were mixed gently by inversion. DNA was precipitated with a thread-like appearance. DNA precipitate was observed then centrifuged at 15,000 for 20 min and carefully the supernatant were pipette out, while retaining the DNA pellets. If DNA pellets are visible, the solution was leaved at $-20^{\circ} \mathrm{C}$ overnight, then centrifuged, discard supernatant, and retains the pellets. $500 \mu \mathrm{l}$ of $-20^{\circ} \mathrm{C} 70 \%$ ethanol were added into DNA pellets, the tube was inverted a few times, and then was centrifuged at 15,000 for $20 \mathrm{~min}$ at $0^{\circ} \mathrm{C}$. Carefully the solution was pipette out, saving the DNA pellets in the microtube. The microtubes were leaved open in a fume hood for about 15-20 min to allow ethanol to evaporate. The pellet was resuspend in $75 \mu$ of sterilized distilled water or Tris-EDTA (TE) buffer, the pellet was leaved to resuspend overnight at room temperature in the fume hood. The DNA concentration was quantified with a spectrophotometer 


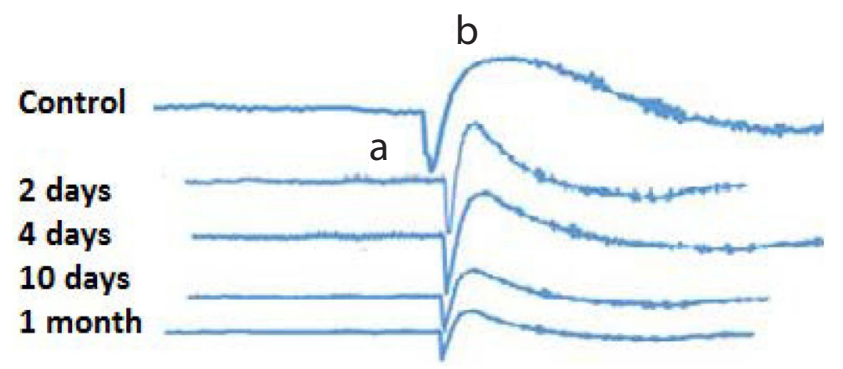

Figure 1. Typical records of ERG before and after injection (2, 4, 10 days and one month) of methotrexate (MTX).

(Fisher Scientific, NanoDrop, model 2000C). Samples of $10 \mu \mathrm{g}$ of DNA were loaded in each well of a $2.0 \%$ agarose gel. Electrophoresis was performed at 3 to $5 \mathrm{~V} / \mathrm{cm}$. DNA was stained with a 1:10,000 dilution of SYBR Green I (Molecular Probes, Eugene, OR) in Tris borate EDTA (TBE) buffer (89 $\mathrm{mM}$ Tris base, $89 \mathrm{mM}$ boric acid, $1 \mathrm{mM}$ EDTA, pH 8), visualized by transillumination with UV light, and photographed (Lam et al. 1999).

\section{Caspase-3 colorimetric activity assay}

Retinal caspase-3 activity was measured with the use of specific colorimetric kit (R\&D Systems, Lille, France) according to the manufacturer's instructions. Briefly, two retinas of one rabbit were homogenized in the kit's lysis buffer. The protein content was measured using Bradford Folin's reagent method (Bio-Rad Laboratories). Proteins were incubated at $37^{\circ} \mathrm{C}$ for 1.5 hours with caspase-specific substrates (DEVD-pNA for caspase-3) in the kit's reaction buffer. The absorbance of the sample was read at $405 \mathrm{~nm}$ and the activity level of caspase- 3 was directly proportional to the color reaction (Kermer et al. 1999).

\section{Statistical analysis}

Analysis of variance (ANOVA) was performed on the electroretinographic and apoptotic cell number, or caspase activity. If ANOVA was significant, multiple comparisons were made to determine which pairs of mean values were different. Significant differences between groups were assessed with the post hoc Newman-Keuls test; the significance level was set at $p<0.05$.

\section{Results}

\section{$E R G$}

A typical record of ERG before and after injection of methotrexate is shown in Figure 1.The baseline of the ERG is the standing potential of the eye. The amplitude of a-wave

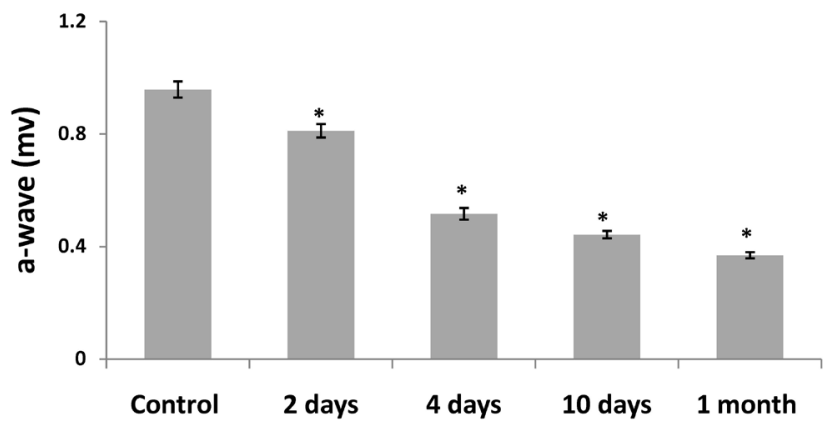

Figure 2. Amplitude of a-wave in control rabbits and after intravitreal injection $\left(2,4,10\right.$ days and one month) of methotrexate. ${ }^{\star}$ statistically significant $p<0.05$

is measured from the baseline to the a-wave through while b-wave is measured from the peak of the a-wave to the peak of the b-wave. The amplitude of a-wave has mean values of $0.958 \pm 0.029 \mathrm{mV}$ and the $\mathrm{b}$-wave is $1.769 \pm 0.053 \mathrm{mV}$ for control group.

The mean and standard deviation of the amplitudes of aand $b$-waves for the different periods are shown in Figures 2 and 3. It is clear from the figures that the ERG was strongly affected by injection of MTX.

It is noticed that there was an obvious effect in the second group which was injected with MTX in the form of reduction in a- and b-wave amplitudes that increase with time in both of wave in comparison with control group along the period of experiment. The percentage difference was $15 \%$ and $4 \%$ for a- and b-wave amplitudes, respectively, i.e. a-wave is more affected than b-wave. Percentiles continues to increase till reach to $61 \%$ and $58 \%$ for a- and b-wave amplitudes, respectively $(p<0.05)$.

The b/a ratio is also calculated which serve as a quantitative index and an examination to the vitality of the retina which found to be 1.85 for control. The ratios for the injected groups increase and tend to be constant along the period of experiment as shown in Figure 4.

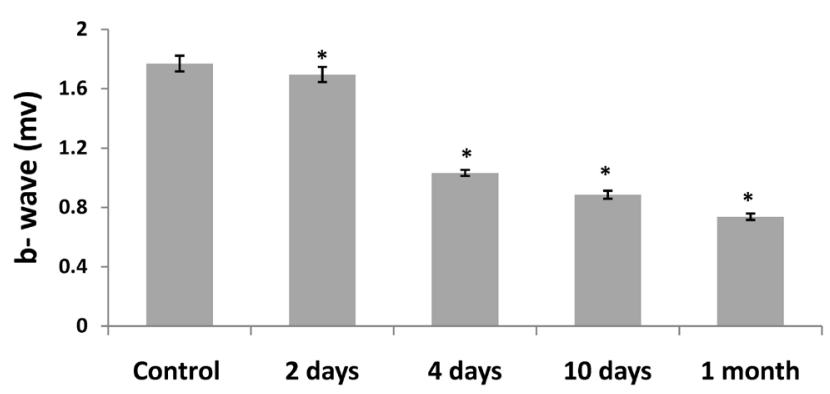

Figure 3. Amplitude of b-wave for control rabbits and after 2, 4, 10 days and one month of intravitreal injection of methotrexate (MTX). ${ }^{\star}$ statistically significant $\left.p<0.05\right)$. 


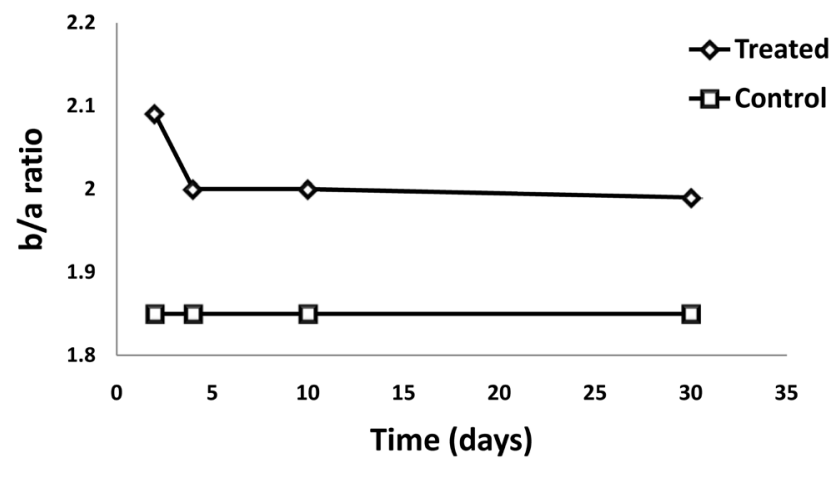

Figure 4. Ratio of b/a waves after 2, 4, 10 days and one month of intravitreal injection of methotrexate (MTX) and for control group.

\section{DNA fragmentation}

Agarose gel electrophoresis of retinal DNA obtained at various times after the intravitreal injection of MTX (Figure 5) showed a time-dependent appearance of the typical ladder pattern of internucleosomal fragmentation, a characteristic of apoptosis. A faint ladder pattern was barely noticeable at 2 days but maximum band intensity was noted after 30 days of injection. No DNA ladder was present in the control retina. Table 1 illustrate the number of bands, bp and percentage of $\mathrm{bp}$ in each band for ladder and all groups injected with MTX compared with control retina. As shown in the table, the ladder reflects 10 bands with different percentage in contrast to control that lake of DNA ladder. Two days after MTX injection, five bp fragmentations (180, 360, 540,654 and $1079 \mathrm{bp}$ ) were appeared. The fragmentations

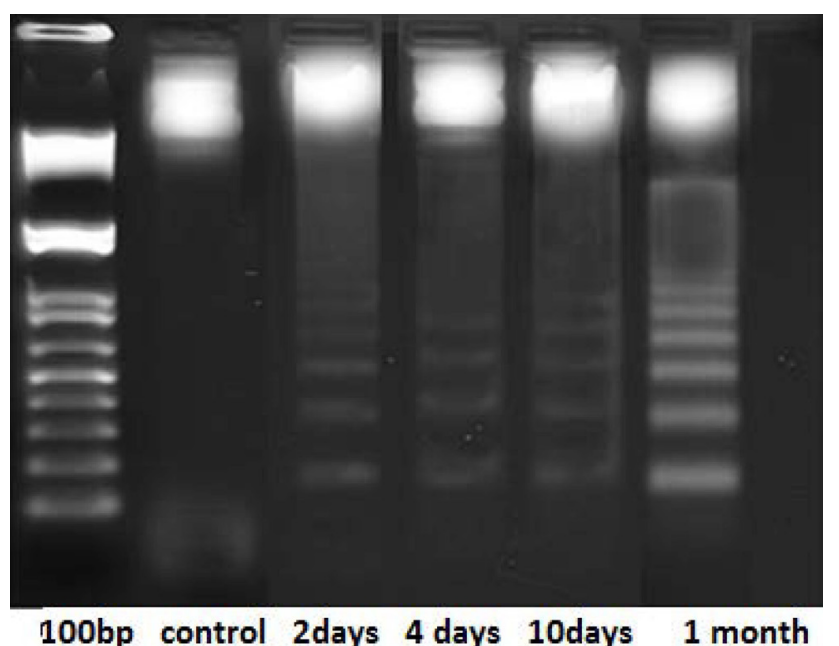

Figure 5. DNA fragmentation analysis by gel electrophoresis. The retinal samples from control and after 2, 4, 10 days and one month of intravitreal injection of methotrexate. The first column is the marker (100 bp). were increased for six bp after 4 and 10 days of intravitreal injection of MTX. Seven bands multiple of 180-200 bp were observed after one month of MTX injection.

\section{Caspase-3 activity}

Caspase-3 is a known key molecule in the process of apoptosis, playing an important role in the execution of apoptosis. Relative caspase- 3 activity percentage was $86 \pm 4$ for control group as shown in Figure 6. A statistically significant $(p<$ $0.05)$ increase of caspase- 3 activity was observed after 2 , 4, 10 and 30 days after intravitreal injection of MTX. The maximum increase of relative caspase- 3 activity was $283 \pm$ 6 that appeared after one month of MTX.

\section{Discussion}

MTX is a cytotoxic chemotherapeutic agent, widely used not only for malignancies but also for various inflammatory diseases such as psoriasis, dermatomyositis, sarcoidosis, and rheumatoid arthritis. MTX-induced toxicity appears to be a consequence of the interaction of many factors, including the dosing schedule and length of treatment, patient risk factors, type of disease, and the presence of molecular apoptotic factors (Ayromlou et al. 2011).

The therapeutic use of MTX has been limited by its toxicity for the proliferating cells, especially the rapidly dividing cells of intestinal crypts. MTX is a dihydrofolate reductase (DHFR) inhibitor that blocks DNA synthesis by depleting the intracellular-reduced folate pools required for the biosynthesis of purines and thymidine, and leads to cell cycle arrest and apoptosis in many cell types (Li et al. 2009).

Our study showed that ERG wave was affected by the injection of MTX. These changes are in the form of reduced amplitude of the ERG waves (a- and b-), which suggests functional changes in the retina. This finding is in agreement with Omoti (2006) and Ozkan et al. (2013). Retina

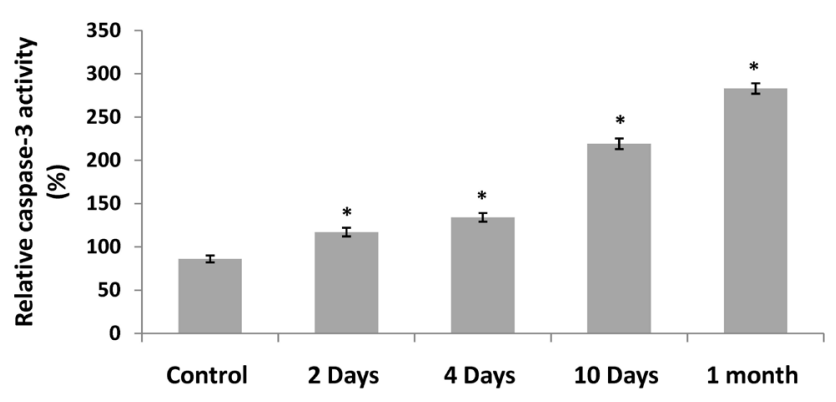

Figure 6. Relative caspase-3 activity after 2, 4, 10 days and one month of intravitreal injection of methotrexate (MTX) compared to control. ${ }^{*}$ statistically significant $p<0.05$. 
Table 1. Bands and percentage of bp fragmentation for ladder and different groups intravitreally injected with methotrexate (MTX) compared to control

\begin{tabular}{|c|c|c|c|c|c|c|c|c|c|c|c|c|}
\hline \multirow{3}{*}{$\begin{array}{l}\text { Lane } \\
\text { Band }\end{array}$} & \multirow{2}{*}{\multicolumn{2}{|c|}{ Ladder }} & \multirow{2}{*}{\multicolumn{2}{|c|}{ Control }} & \multicolumn{8}{|c|}{ After MTX } \\
\hline & & & & & \multicolumn{2}{|c|}{2 Days } & \multicolumn{2}{|c|}{4 Days } & \multicolumn{2}{|c|}{6 Days } & \multicolumn{2}{|c|}{ One month } \\
\hline & bp & $\%$ & $\mathrm{bp}$ & $\%$ & $\mathrm{bp}$ & $\%$ & bp & $\%$ & bp & $\%$ & bp & $\%$ \\
\hline 1 & 1000 & 37.79 & 1070 & 100 & 1079 & 42.25 & 1074 & 32.43 & 1074 & 53.34 & 1074 & 59.04 \\
\hline 2 & 900 & 26.45 & - & - & 654 & 13.88 & 802 & 8.22 & 748 & 2.83 & 815 & 7.90 \\
\hline 3 & 800 & 6.43 & - & - & 540 & 16.03 & 643 & 11.21 & 654 & 3.31 & 720 & 7.49 \\
\hline 4 & 700 & 6.68 & - & - & 360 & 10.03 & 540 & 12.81 & 540 & 12.68 & 637 & 8.30 \\
\hline 5 & 600 & 3.03 & - & - & 180 & 17.81 & 360 & 16.27 & 360 & 15.69 & 540 & 3.80 \\
\hline 6 & 500 & 5.18 & - & - & - & - & 180 & 19.06 & 180 & 12.15 & 360 & 9.34 \\
\hline 7 & 400 & 2.43 & - & - & - & - & - & - & - & - & 180 & 4.13 \\
\hline 8 & 300 & 2.64 & - & - & - & - & - & - & - & - & - & - \\
\hline 9 & 200 & 3.50 & - & - & - & - & - & - & - & - & - & - \\
\hline 10 & 100 & 5.87 & - & - & - & - & - & - & - & - & - & - \\
\hline
\end{tabular}

has a relatively small mass and highly enriched with blood supply and long-chain polyunsaturated fatty acids therefore it is highly susceptible to toxic substances (Peponiset al. 2010). The a-wave originates mainly from the photoreceptors cells. Its amplitude depends on the ability of the rhodopsin in the photoreceptor to absorb light. Retinal circulation and the efficient interactions between the a- and b-wave affected $\mathrm{b}$-wave which is mainly from the middle retinal layer (Kolb et al. 2011). So this explanation may give a clear idea about the deformation obtained in the ERG.

The results also indicated that intravitreal injection of MTX that affects function of the retina accompanied by apoptosis and significant increase of caspase- 3 activity. All these changes after injection of MTX can be attributed to its induced toxicity. Several anti-tumour drugs cause adverse affects due to oxygen radicals, hydrogen peroxides and reactive oxygen species (ROS) generation. The mechanism of MTX-induced toxicity may be due to the production of hydroxyl radicals that lead to cellular damage (Miyazono et al. 2004). High activities of purine-catabolizing enzymes such as adenosine deaminase (ADA) and xanthine oxidase (XO) activate ROS generation. The mitochondrial membrane dysfunction leads to impaired ATP metabolism with increased production of purine degradation products such as adenosine, inosine, hypoxanthine and xanthine which are substrates for ADA and XO (Fadillioglu et al. 2003).Free radicals are expected to play a role in MTXinduced toxicity. Lipid peroxidation, mediated by oxygen free radicals, is believed to be an important cause of destruction and damage to cell membranes and has been suggested to be a contributing factor to the development of MTX-mediated tissue damage. Tissues with a high proportion of membrane lipids and a high tissue oxygen concentration are most sensitive to damage by oxidative stress. The retina has a high oxygen tension $(70 \mathrm{mmHg})$ which makes it very vulnerable to oxidative stress. Moreover, the retina possess very high levels of polyunsaturated fatty acids which further increase the sensitivity to oxidative damage and lipid peroxidation of cell membranes as well as phenomena of both cell death type's apoptosis or necrosis (Saenz-de-Viteri et al. 2014).

Caspases (cysteine aspartate-specific proteases) are the first proteases that coordinate and execute the apoptotic process in many apoptotic systems (Chang and Yang 2000). These proteins are synthesized as inactive zymogens and are activated by proteolytic cleavage to form a tetramer (Earnshaw et al. 1999). Two major pathways, leading to the degradation of key survival proteins, have been described for caspase activation: the extrinsic pathway initiated by ligand binding to a death receptor and the intrinsic pathway involving the release of cytochrome $c$ from the mitochondrial intermembrane space into the cytosol (Perche et al. 2007). Caspase- 3 is a known key molecule in the process of apoptosis, playing an important role in the execution of apoptosis. Some studies have shown that caspase- 3 activation is closely related to the apoptosis of pigment epithelial cell, outer nuclear layer cell and ganglion cell caused by retinal damage (Tian and Zhu 2013). In conclusion, our experiment verified that apoptosis existed in retinal cells in the early stage of intravitreal injection of MTX to rabbits since the significant increase of caspase- 3 that appeared after 2 days of injection. Also retinal electroretinogram was affected which suggests functional changes in the retina.

\section{References}

Ayromlou H., Hajipour B., Hossenian M. M., Khodadadi A., Vatankhah A. M. (2011): Oxidative effect of methotrexate administration in spinal cord of rabbits. J. Pak. Med. Assoc. Nov. 61, 1096-1099 
Buchi E. R., Bernauer W., Daicker B. (1994): Cell death and disposal in retinoblastoma: an electron microscopic study. Graefes Arch. Clin. Exp. Ophthalmol. 232, 635-645 http://dx.doi.org/10.1007/BF00171377

Chang H.Y., Yang X. (2000): Proteases for cell suicide: functions and regulation of caspases. Microbiol. Mol. Biol. Rev. 64, 821-846 http://dx.doi.org/10.1128/MMBR.64.4.821-846.2000

Compton M. M. (1992): A biochemical hallmark of apoptosis: internucleosomal degration of the genome. Cancer Metastasis Rev. 11, 105-119 http://dx.doi.org/10.1007/BF00048058

Cook B., Lewis G. P., Fisher S. K., Adler R. (1995): Apoptotic photoreceptor degeneration in experimental retinal detachment. Invest. Ophthalmol. Vis. Sci. 36, 990-996

DeAngelis L. M., Yalahom J., Thaler H. T. (1992): Combined modality therapy for primary CNS lymphoma. J. Clin. Oncol. 10, 635-643

Earnshaw W. C., Martins L. M., Kaufmann S. H. (1999): Mammalian caspases: structure, activation, substrates, and functions during apoptosis. Annu. Rev. Biochem. 68, 383-424 http://dx.doi.org/10.1146/annurev.biochem.68.1.383

Fadillioglu E., Erdogan H., Iraz M., Yagmurca M. (2003): Effects of caffeic acid phenethyl ester against doxorubicininduced neuronal oxidant injury. Neurosci. Res. Commun. 33, 132-138 http://dx.doi.org/10.1002/nrc.10089

Frenkel S., Hendler K., Siegal T., Shalom E., Péer J. (2008): Intravitreal methotrexate for treating vitreoretinal lymphoma: 10 years of experience. Br. J. Ophthalmol. 92, 383-388 http://dx.doi.org/10.1136/bjo.2007.127928

Gerschenson L. E., Rotello R. J. (1992): Apoptosis: a different type of cell death. FASEB J. 6, 2450-2455

Johnson E. M., Deckwerth T. L. (1993): Molecular mechanisms of developmental neuronal death. Annu. Rev. Neurosci. 16, 31-46 http://dx.doi.org/10.1146/annurev.ne.16.030193.000335

Kermer P., Klöcker N., Labes M., Thomsen S., Srinivasan A., Bähr M. (1999): Activation of caspase-3 in axotomized rat retinal ganglion cells in vivo. FEBS Lett. 453, 361-364 http://dx.doi.org/10.1016/S0014-5793(99)00747-4

Kolb H., Nelson R., Fernandez E., Jones B. (2011): The organization of the retina and visual system. Copyright $\odot$ web vision powered by word press. University of Utah

Lam T. T., Abler A. S., Tso M. O. (1999): Apoptosis and caspases after ischemia-reperfusion injury in rat retina. Invest. Ophthalmol. Vis. Sci. 40, 967-975

Li T., Ito K., Sumi S., Fuwa T., Horie T. (2009): Protective effect of aged garlic extract (AGE) on the apoptosis of intestinal epithelial cells caused by methotrexate. Cancer Chemother. Pharmacol. 63, 873-880 http://dx.doi.org/10.1007/s00280-008-0809-4

Li K., Wu D., Chen X., Zhang T., Zhang L., Yi Y., Miao Z., Jin N., Bi X., Wang H., Xu J., Wang D. (2014): Current and emerging biomarkers of cell death in human disease. Biomed. Res. Int. 2014, 1-10 http://dx.doi.org/10.1155/2014/690103

Miyazono Y., Gao F., Horie T. (2004): Oxidative stress contributes to methotrexate-induced small intestinal toxicity in rats. Scand. J. Gastroenterol. 39, 1119-1127 http://dx.doi.org/10.1080/00365520410003605

Nelson D. F. (1999): Radiotherapy in the treatment of primary central nervous system lymphoma. J. Neurooncol. 43, 241-247 http://dx.doi.org/10.1023/A:1006206602918

Omoti A. E., Omoti C. E. (2006): Ocular toxicity of systemic anticancer chemotherapy. Pharmacy Practice 4, 55-59 http://dx.doi.org/10.4321/S1885-642X2006000200001

Ozkan E. B, Ozcan A. A., Sekeroglu H. T., Kuyucu Y., Ozgun H., Polat S. (2013): Intravitreal injection of methotrexate in an experimental rabbit model: Determination of ultrastructural changes. Indian J. Ophthalmol. 61, 329-333 http://dx.doi.org/10.4103/0301-4738.109518

Peponis V., Kyttaris V. C., Chalkiadakis S. E., Bonovas S., Sitaras N. M. (2010): Ocular side effects of anti-rheumatic medications: what a rheumatologist should know. Lupus 19, 675-682 http://dx.doi.org/10.1177/0961203309360539

Perche O., Doly M., Ranchon-Cole I. (2007): Caspase-dependent apoptosis in light-induced retinal degeneration. Invest. Ophthalmol. Vis. Sci. 48, 2753-2759

http://dx.doi.org/10.1167/iovs.06-1258

Peterson K., Gordon K. B., Heinemann M. H., DeAngelis L. M. (1993): The clinical spectrum of ocular lymphoma. Cancer 72, 843-849 http://dx.doi.org/10.1002/1097-0142(19930801)72:3<843::AID-CNCR2820720333>3.0.CO;2-\#

Saenz-de-Viteri M., Heras-Mulero H., Fernández-Robredo P., Recalde S., Hernández M., Reiter N., Moreno-Ordu-a M., García-Layana A. (2014): Oxidative stress and histological changes in a model of retinal phototoxicity in rabbits. Oxid. Med. Cell. Longev. 2014, 637137 http://dx.doi.org/10.1155/2014/637137

Taylor S. R., Banker A., Schlaen A., Couto C., Matthe E., Joshi L., Menezo V., Nguyen E., Tomkins-Netzer O., Bar A., Morarji J., McCluskey P., Lightman S. (2013): Intraocular methotrexate can induce extended remission in some patients in noninfectious uveitis. Retina 33, 2149-2154 http://dx.doi.org/10.1097/IAE.0b013e31828ac07d

Tian X. M., Zhu Y. (2013): Apoptosis of rabbit retinal cell after eyeball rupture. Asian Pac. J. Trop. Med. 6, 273-279 http://dx.doi.org/10.1016/S1995-7645(13)60056-5

Vaux D. L. (1993): Toward an understanding of the molecular mechanisms of physiological cell death. Proc. Natl. Acad. Sci. USA 90, 786-789 http://dx.doi.org/10.1073/pnas.90.3.786

Webb S. J., Harrison D. J., Wyllie A. H. (1997): Apoptosis: an overview of the process and its relevance in disease. Adv. Pharmacol. 41, 1-34

http://dx.doi.org/10.1016/S1054-3589(08)61052-2

Williams G. T., Smith C. A. (1993): Molecular regulation of apoptosis: genetic controls on cell death. Cell 74, 777-779 http://dx.doi.org/10.1016/0092-8674(93)90457-2

Wyllie A. H. (1992): Apoptosis and the regulation of cell numbers in normal and neoplastic tissue: an overview. Cancer Metastasis Rev. 11, 95-103 http://dx.doi.org/10.1007/BF00048057

Received: July 29, 2015

Final version accepted: September 22, 2015

First published online: February 2, 2016 